\title{
Relação entre Política urbana e habitacional: instrumentos urbanísticos em apoio ao provimento da habitação social sustentável
}

\author{
Relationship between urban and housing policy: urbanistic instruments \\ in order to support the provision of sustainable social housing \\ Relación entre política urbana y política de vivienda: instrumentos \\ urbanos para apoyar la provisión de vivienda social sostenible
}

Cristina Maria Correia de Melo ${ }^{1}$ Maria do Carmo de Lima Bezerra ${ }^{2}$

\section{Resumo}

MELO, C. M. C. de.; BEZERRA, M. do C. de L. Relação entre Política urbana e habitacional: instrumentos urbanísticos em apoio ao provimento da habitação social sustentável. Rev. CઐTrópico, $\boldsymbol{v} . \mathbf{4 4}, \boldsymbol{n}$. 1, p. 73-99, 2020. DOI: https://doi.org/10.33148/cetropicov44n1(2020)art4

O acesso à habitação é condição básica para a conquista do direito à cidade sustentável, disposto no Estatuto da Cidade, norma balizadora dos Planos Diretores Urbanos no país. O tema tem ocupado pouco espaço na literatura urbanística sobre sustentabilidade, dando a entender que o provimento de moradia, seja em que condição ocorra, já constituiria um atributo de sustentabilidade da cidade. O estudo visa verificar o grau de sinergia entre as decisões de política urbana e política habitacional para alcance da cidade sustentável. Utiliza como método a identificação dos atributos espaciais do modelo de cidade resiliente e cidade compacta para verificar, entre os instrumentos do Estatuto da Cidade, quais apoiariam decisões de localização de habitação na estrutura urbana, de modo que tais atributos fossem alcançados. Como estudo empírico se tomou a aplicação dos instrumentos: Zonas Especiais de Interesse Social - ZEIS de vazio; Operações Urbanas Consorciadas OUC e Outorga Onerosa do Direito de Construir - OODC para verificar como eles dialogaram com o provimento de habitação de interesse social. Os resultados sugerem que o grau de integração entre instrumentos de política urbana e política habitacional são muito baixos e que as decisões de provimento da habitação visam apenas dados quantitativos não estando em pauta a estruturação sustentável do tecido urbano.

Palavras-chave: Habitação de Interesse Social. Habitação sustentável. Cidade sustentável.

\footnotetext{
Doutoranda no Programa de Pós Graduação da Faculdade de Arquitetura e Urbanismo da Universidade de Brasília, área Projeto e Planejamento. Analista de Planejamento Urbano e Infraestrutura da Secretaria de Estado de Desenvolvimento Urbano e Habitação do Distrito Federal. E-mail: cristina.mello.cmc@gmail.com Orcid: https://orcid.org/0000-0003-1153-9899

2 Doutora em Estruturas Ambientais Urbanas (USP). Professora Associada IV da Universidade de Brasília atuando no Programa de Mestrado e Doutorado da Universidade de Brasília. E-mail: mdclbezerra@gmail.com Orcid: https://orcid.org/0000-0002-7736-5265
} 


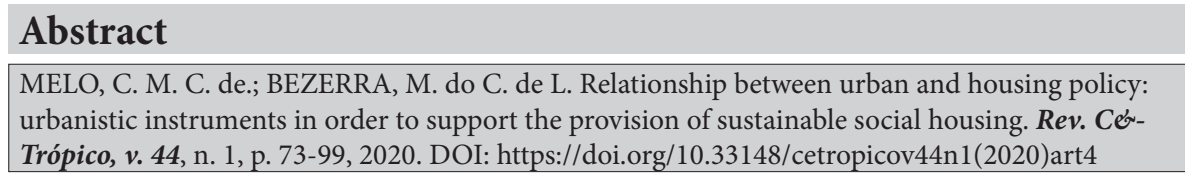

The access to housing is a basic condition for the achievement of the right to a sustainable city, and is laid down in the "Estatuto da Cidade" (city statute), a guideline for Urban Master Plans in the country. The theme has occupied little space in the urban literature on sustainability, suggesting that the provision of housing, in whatever condition occurs, would already constitute an attribute of sustainability in the city. The study aims to verify the degree of synergy between urban policy and housing policy decisions to reach a sustainable city. It uses as a method the identification of the spatial attributes of the model of resilient city and compact city to verify, among the instruments of the "Estatuto da Cidade", which would support decisions of housing location in the urban structure, so that such attributes were achieved. As an empirical study, the application of the instruments was taken: Special Areas of Social Interest (ZEIS de vazios); Consortium Urban Operations (OUC) and Onerous Grant of the Right to Build (OODC) to verify how they dialogued with the provision of social housing. As a result, it was found that the degree of integration between urban policy and housing policy instruments is very low and that decisions to provide housing are aimed only at quantitative data, and the sustainable structuring of the urban city is not on the agenda.

Keywords: Interest Housing. Sustainable housing. Sustainable city.

\section{Resumen}

MELO, C. M. C. de.; BEZERRA, M. do C. de L. Relación entre política urbana y política de vivienda: instrumentos urbanos para apoyar la provisión de vivienda social sostenible. Rev. CひTrópico, v. 44, n. 1, p. 73-99, 2020. DOI: https://doi.org/10.33148/cetropicov44n1(2020)art4

El acceso a la vivienda es una condición básica para lograr el derecho a una ciudad sostenible, como se establece en el Estatuto de la Ciudad, una norma rectora para los Planes Maestros Urbanos en el país. El tema ha ocupado poco espacio en la literatura urbana sobre sostenibilidad, lo que sugiere que la provisión de vivienda, cualquiera que sea la condición, ya constituiría un atributo de sostenibilidad en la ciudad. El estudio tiene como objetivo verificar el grado de sinergia entre la política urbana y las decisiones de política de vivienda para llegar a una ciudad sostenible. Utiliza como método la identificación de los atributos espaciales del modelo de ciudad resiliente y ciudad compacta para verificar, entre los instrumentos del Estatuto de la Ciudad, lo que respaldaría las decisiones de ubicación de la vivienda en la estructura urbana, para que dichos atributos se lograran. Como estudio empírico, se tomó la aplicación de los instrumentos: Zonas especiales de interés social - ZEIS de vacio; Operaciones urbanas del consorcio - OUC y Onerous Grant of the Right to Build - OODC para verificar cómo dialogaron con la provisión de viviendas sociales. Los resultados sugieren que el grado de integración entre la política urbana y los 
instrumentos de política de vivienda es muy bajo y que las decisiones de proporcionar vivienda apuntan solo a datos cuantitativos y que la estructuración sostenible del tejido urbano no está en la agenda.

Palabras clave: Vivienda de Interés Social. Vivienda sostenible. Ciudad sostenible.

Data de submissão: 07/02/2020

Data de aceite: $24 / 04 / 2020$

\section{Introdução}

A concepção de desenvolvimento urbano esteve vinculada, desde sua origem, à promoção da melhoria da vida dos habitantes da cidade, entendida como o acesso a serviços que garantissem sua saúde e promoção social e econômica. A ideia de proteção ambiental e a qualidade do espaço urbano produzido, para fazer frente a integração social, ganhou maior relevância a partir da década de 1980, quando o conceito de sustentabilidade passou a fazer parte das discussões sobre o urbano. Nesse contexto, se passa a discutir os atributos da cidade sustentável associando a apregoada qualidade de vida da população à qualidade ambiental, demandando práticas de planejamento urbano que articulem a funcionalidade da cidade, antes determinante, com a integração social e preservação do meio ambiente. (RUEDA, 2000; ROGERS; GUMUCHDJIAN, 2001).

$\mathrm{O}$ acesso à habitação, um dos componentes da estrutura urbana, é condição básica para a conquista do direito à cidade, conceito que é valido tanto no modelo de planejamento tradicional quanto no sustentável. Entretanto, direito à cidade possui conotação diferente nos dois modelos, um se refere à propriedade da terra e o outro ao acesso à moradia que promova condições de acessibilidade aos serviços e oportunidade que a urbanidade pode conferir a seus habitantes. O tema, assim colocado, tem ocupado pouco espaço na vasta literatura urbanística sobre sustentabilidade, o que tem levado à manutenção das antigas práticas de provimento da habitação, mesmo por agentes técnicos e institucionais que propagam como orientação a sustentabilidade das políticas públicas urbanas.

Observa-se que, na maioria das cidades, a política habitacional é tratada de forma dissociada da política urbana, sem o estabelecimento de uma relação entre os instrumentos de gestão da cidade e sua capacidade de facilitar ou dificultar a localização habitacional dotada de atributos que propiciam melhor qualidade de vida e ambiental às cidades. A política habitacional promovida pelos programas governamentais é entendida como uma edificação em sua condição de abrigo, sem discussão sobre sua inserção urbana.

A visualização dessa contradição se encontra nas recentes experiências de programas habitacionais no Brasil $^{3}$, onde se reproduz a prática já vivenciada na década

\footnotetext{
3 Atualmente no Brasil a habitação social é provida por meio do Programa Minha Casa Minha Vida - PMCMV do Governo Federal, que vem sendo implantado desde 2009 de acordo com a Lei $n^{\circ}$ 11.977/2009.
} 
de 1970, com a construção de conjuntos habitacionais segregados da estrutura urbana consolidada, gerando um tecido urbano fragmentado, disperso, com exclusão social da população de baixa renda.

É certo que a habitação pode ser discutida a partir de vários pontos de vista: da participação social com garantias de que contextos culturais distintos sejam preservados; dos meios de financiamento que promovam equidade social; dos sistemas construtivos para atribuir salubridade e segurança, mas a abordagem que aqui se coloca é o da estruturação urbana que proporcione vivências de urbanidade e de qualidade ambiental ao conjunto da cidade, ou em outras palavras, uma abordagem com a visão do ordenamento territorial urbano que possui na localização habitacional sua mais forte manifestação. Assim, dentro dessa perspectiva, a discussão aqui procedida se dá sobre a forma de provimento da habitação de interesse social e sua contribuição para promover a cidade sustentável ${ }^{4}$.

A leitura a ser realizada considera as características de cidade resiliente e compacta como aquelas que sintetizam um conjunto de atributos espaciais que corroboram a ideia de sustentabilidade por meio de instrumentos urbanísticos que nos apresenta o Estatuto da Cidade. Esses podem ser adotados pelos Planos Diretores de Ordenamento Territorial em favor de uma estrutura urbana com as qualificações espaciais que permitam o provimento de uma moradia sustentável pelos programas habitacionais. Por fim, visa verificar até que ponto está ocorrendo uma articulação entre política urbana e política habitacional se colocando a moradia como estruturante do espaço urbano.

\section{Metodologia (material e método)}

Para enfrentar o tema, parte-se do estudo sobre alguns conceitos que definem as características das cidades sustentáveis, com o intuito de identificar as recorrências de atributos no que se refere à estrutura espacial da cidade. A revisão bibliográfica destacou as características dos modelos de cidades resilientes e de cidades compactas como os que melhor expressam a espacialidade da ideia de sustentabilidade e viabilizam um diálogo com as ações de natureza próprias do planejamento urbano. Nas cidades, respondem aos aspectos necessários para o alcance da qualidade de vida e ambiental, considerando como base da pesquisa bibliográfica autores como Bezerra (2018); Ribas (2003); Rogers e Gumuchdjian (2001); Sachs (2002); Santos e Hardt (2013); e Tudela (1997).

Em seguida, foram estudados os instrumentos urbanísticos do Estatuto da Cidade com o objetivo de identificar as correlações, entre o que possibilita em termos de estruturação urbana, para alcance dos atributos antes identificados. Essas correspondências foram capazes de auxiliar na obtenção de uma localização para a habitação de interesse social que responda a sustentabilidade da cidade e da habitação. As informações encontradas foram sistematizadas em quadros de análise com o intuito de,

\footnotetext{
Estatuto da Cidade - Lei ${ }^{\circ} 10.257 / 2001$, Art. $2^{\circ}$, inciso I e Lei ${ }^{\circ} 11.124 / 2005$, Art. $2^{\circ}$, inciso I.
} 
tanto apoiar a avaliação, quanto subsidiar novas configurações urbanas promotoras de moradia sustentável.

De posse do resultado dessa base teórica, se procedeu a uma leitura da estratégia de promoção de habitação social, verificando se os instrumentos urbanísticos adotados foram capazes de viabilizar a moradia e a estrutura urbana desejável. Os estudos se referem a casos de adoção de diferentes instrumentos, dentre os identificados, em diferentes contextos urbanos, que são apresentados com o intuito de exemplificar as possibilidades e dificuldades de articular política urbana com a habitacional. Foram utilizados como exemplos os instrumentos ZEIS de vazio, Operação Urbana Consorciada e Outorga Onerosa do Direito de Construir.

\section{Referências conceituais e analíticas}

A associação da noção de sustentabilidade ao debate sobre desenvolvimento das cidades tem origem nas rearticulações políticas de atores envolvidos na produção do espaço urbano. Nesse contexto, desenvolvem-se várias linhas de abordagem da sustentabilidade urbana, algumas de cunho social e ecológico, as quais visavam a responder às iniquidades que fizeram o planejamento ser desacreditado, dado o déficit socioambiental da urbanização.

As marcas da ênfase do planejamento tradicional se encontram nas ações propostas e, também, no que impediu de ser feito em função do modelo de conceber cidades, idealizado e rígido em suas origens funcionalistas. As consequências podem ser visualizadas na dispersão urbana que gera impactos sobre a base de recursos naturais, amplia os custos de urbanização e de sua manutenção e gera espaços sem urbanidade. No caso dos países de urbanização desigual, que não podem pagar por esses custos, gerou cidades constituídas por periferias, sem infraestrutura e serviços, formadas por assentamentos irregulares e/ou conjuntos habitacionais de baixa renda promovidos pelo Estado.

\subsection{Atributos da cidade e da habitação sustentável}

A concepção de cidade sustentável, do ponto de vista do ordenamento territorial, inclui a busca por uma forma urbana que possua um conjunto de características que possa ser facilitadora da integração social e capaz de gerar menor pressão sobre os recursos naturais e financeiros da sociedade. Tudo associado à participação social e adequações das soluções às especificidades dos lugares.

Dentro dessa perspectiva, cabe discutir as qualificações que uma habitação sustentável deve possuir para que se alcancem cidades sustentáveis, uma vez que esse é o componente da estrutura urbana que ocupa mais de $70 \%$ da cidade. Até o momento, pelo que foi apontado, parece que a visão predominante tem sido de que, prover moradia, seja em que condições ocorram, já atenderia a necessidade habitacional e, por decorrência, os objetivos de sustentabilidade estariam sendo alcançados. 
Os estudos teóricos sobre sustentabilidade indicam que as características necessárias para a criação de habitações mais sustentáveis, ou seja, aquela que considera a inserção da habitação no seu espaço urbano, deve levar em consideração novos arranjos de uso e ocupação do solo urbano. As diferentes correntes apontam para o desenvolvimento de diferentes formas urbanas. Newton (2000) apresenta cinco tipos de configurações: fringe cities, corridor cities, edge cities, compact e dispersed cities ${ }^{5}$. Porém, de acordo com Costa (2007), é em torno da generalização dos termos cidade compacta e cidade dispersa que a discussão ganhou relevância na década de 1980, quando começaram a se estabelecer relações entre a morfologia urbana e qualidade de vida e ambiental. Do ponto de vista da pressão da urbanização sobre a base de recursos naturais, desponta a concepção da cidade resiliente como aquela que articula a ocupação do solo urbano aos condicionantes do meio, como forma de reduzir impactos socioambientais.

Nesse sentido, vale destacar os parâmetros relativos a cidades resilientes e compactas $^{6}$, que apontam para o provimento da moradia em um contexto de diversidade social e de usos do solo, evitando a segregação e proporcionando um espaço dotado de serviços, equipamentos sociais e atividades econômicas, que seja facilitador do acesso da população a toda a cidade.

Em ambos os casos, o tema da compactação urbana está presente e associado à forma urbana sustentável. Rueda (2002) define a cidade compacta como sendo aquela que possui características mediterrâneas, densa e que pode ser percorrida a pé ${ }^{7}$, sendo a cidade do pedestre e não do automóvel. É um modelo que permite conceber uma vida social coesa, com plataforma econômica competitiva, ao mesmo tempo em que se preservam as áreas naturais. A proximidade dos elementos faz com que haja redução do consumo de energia, tempo e solo, propiciando mecanismos de regulação e controle. Na visão dele, compacidade e diversidade são elementos importantes para manter a complexidade das trocas.

Jenks et al.; (1996) consideram que a cidade compacta possui atributos menos nocivos ao meio ambiente, já que são densamente construídas e fazem um uso mais

\footnotetext{
Newton (2000) define as categorias da seguinte maneira - Fringe cities: cidades cujo desenvolvimento ocorre predominantemente na orla urbana; Corridor cities: cidades cujo desenvolvimento ocorre predominantemente ao longo de um corredor linear a partir do núcleo central da cidade, fortemente suportado pelo desenvolvimento do sistema de transportes públicos; Edge cities: cidades que se caracterizam pela ocorrência de crescimento populacional, do emprego e da densidade residencial em nós bem definidos da cidade e simultaneamente pelo desenvolvimento de núcleos de comércio e serviços no exterior da cidade, suportados pelo desenvolvimento da rede viária; Dispersed cities: desenvolvimento contínuo de baixa densidade populacional, com infraestrutura dominada pelo transporte rodoviário; Compact cities: desenvolvimento com altas densidades, possibilidade de melhor estrutura para transporte público.

6 Os atributos espaciais da cidade sustentável devem ser destacados em sua relação com a habitação para obtermos uma caracterização do que é uma habitação sustentável. Pelos estudos teóricos sobre sustentabilidade, se chegou à conclusão de que os atributos das cidades resilientes e compactas são os responsáveis por estas características necessárias.

Rueda (2002) descreve o modelo de cidade compacta e suas características mais importantes. Todavia, sabe-se que nenhuma metrópole pode ser percorrida totalmente a pé. Há ainda, um outro viés que deve ser analisado nessa premissa: ao se promoverem elementos estruturadores da forma compacta em uma metrópole, abre-se a possibilidade de favorecer este tipo de deslocamento.
} 
eficiente do solo urbano, evitando o espalhamento da cidade. Jacobs (2009), ao elaborar uma análise crítica sobre as políticas de planejamento modernistas, atacou a tendência herdada da cidade jardim e sugeriu quatro condições necessárias para permitir a diversidade e renovação urbana: (1) uso misto; (2) pequenos blocos ou quadras curtas; (3) combinação de edifícios com estado de conservação variado; e (4) necessidade de concentração, densificação. Esses atributos mencionados remetem à ideia, portanto, da cidade compacta.

Para Leite e Awad (2012), a cidade compacta é um modelo de desenvolvimento urbano que promove altas densidades de modo qualificado, com adequado planejamento de uso misto do solo urbano, misturando funções urbanas. Gomes (2009) define que a cidade compacta tem como base duas características fundamentais: densidades elevadas e uso de solo diversificado. Juntas, essas duas características traduzem em uma intensificação de uso do solo que poupa área urbanizada, buscando resolver os problemas dentro dos seus próprios limites, evitando a expansão desordenada.

A cidade resiliente, por sua vez, é sempre definida como aquela que possui alta capacidade de resistir, absorver, adaptar-se e recuperar-se da exposição às ameaças, produzindo efeitos de maneira oportuna e eficiente, o que inclui a preservação e restauração de suas estruturas e funções básicas, estando vinculada ainda aos conceitos dinâmicos de desenvolvimento e crescimento urbano. Para assegurar a resiliência de uma comunidade é fundamental atender uma abordagem de envolvimento, de união, de partilha de informação e de implementação dos diversos níveis do conhecimento. (CARVALHO et al., 2013).

Transpondo esse entendimento para o alcance da habitação sustentável, essa deve considerar a prevenção de condições que possam ameaçá-la de exercer suas múltiplas funções como, também, a capacidade de se adaptar a mudanças que ocorram na estrutura urbana onde está inserida. Essa condição só se alcança mediante um planejamento urbano que antecipe e promova as condições de sua inserção multifuncional, como de uma gestão urbana dinâmica, que administre os ajustes necessários para o bom funcionamento da cidade.

As habitações presentes num contexto citadino de miscigenação de funções e de culturas, com várias centralidades, geram um menor consumo de solo urbano, favorecendo a diminuição dos custos com infraestrutura e com meios de transportes motorizados, promovendo os deslocamentos como os de bicicleta e a pé, reduzindo assim, o tráfego nas cidades e viabilizando o transporte público.

Do ponto de vista social, as densidades mais elevadas poderão ajudar a tornar economicamente viável o fornecimento de estruturas de serviços e de lazer, aumentando também a sustentabilidade social. Busca-se uma habitação de interesse social com qualidade de vida para todos, harmonizando o ambiente construído e o ambiente natural. No quadro 1, foram compilados, a partir dos princípios de resiliência e compacidade presentes nos estudos de carvalho et. al. (2013); Costa (2013); ONS (2012); Ribas (2003); Rueda (2000); Sachs (2002); Silva (2000) e Tudela (1997), atributos necessários para o alcance da habitação sustentável. 
Quadro 1: Princípios para alcance de habitação sustentável.

\begin{tabular}{|c|c|}
\hline & Características para alcance de habitações sustentáveis \\
\hline \multirow{14}{*}{ 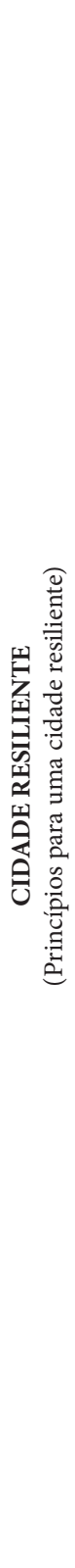 } & $\begin{array}{l}\text { Fomento à coordenação intersetorial e à liderança para redução de riscos e desastres, com } \\
\text { base na participação de grupos de cidadãos e da sociedade civil. }\end{array}$ \\
\hline & $\begin{array}{c}\text { Construção de capacidades institucionais e alocar recursos, com a definição de um } \\
\text { orçamento para a redução do risco de desastres. }\end{array}$ \\
\hline & $\begin{array}{c}\text { Regulamentação do desenvolvimento urbano e local com base em princípios de redução } \\
\text { de riscos, com a atualização permanente de todos os dados sobre os riscos e } \\
\text { vulnerabilidades existentes. }\end{array}$ \\
\hline & $\begin{array}{l}\text { Gestão de risco com base no compromisso com os ecossistemas como forma de mitigar } \\
\text { inundações, tempestades e outros perigos a que a cidade possa estar vulnerável. }\end{array}$ \\
\hline & $\begin{array}{l}\text { Compromisso com a redução da contaminação, melhoria na gestão de resíduos e redução } \\
\text { na emissão dos gases que provocam o efeito estufa. }\end{array}$ \\
\hline & $\begin{array}{l}\text { Atividades econômicas locais diversificadas e implantação de medidas para redução } \\
\text { da pobreza. }\end{array}$ \\
\hline & Plano para continuidade dos negócios, para evitar a interrupção em caso de desastres. \\
\hline & $\begin{array}{c}\text { Criação de incentivos e penalidades para ampliar a resiliência e melhorar o cumprimento das } \\
\text { normas de segurança. }\end{array}$ \\
\hline & $\begin{array}{c}\text { A aplicação e o reforço dos regulamentos de segurança nos processos construtivos com o } \\
\text { objetivo de reduzir os riscos nas infraestruturas. }\end{array}$ \\
\hline & $\begin{array}{c}\text { A existência de programas de educação/formação/sensibilização sobre a redução do risco de } \\
\text { desastres nas escolas. }\end{array}$ \\
\hline & $\begin{array}{l}\text { O desenvolvimento de um sistema de alerta precoce e de gestão de emergência eficaz. É } \\
\text { igualmente importante a realização de exercícios para testar as capacidades das diversas } \\
\text { entidades e da própria comunidade. }\end{array}$ \\
\hline & $\begin{array}{c}\text { Garantia a todos de acesso a serviços básicos e garantia de uma rede de proteção social após } \\
\text { o desastre. }\end{array}$ \\
\hline & Reserva de áreas seguras para atividades estratégicas e para alojamentos. \\
\hline & $\begin{array}{l}\text { Motivação para participação de diversos públicos de interesse em todos os estágios e o } \\
\text { fortalecimento das redes e alianças sociais. }\end{array}$ \\
\hline
\end{tabular}




\begin{tabular}{|c|c|}
\hline \multirow{11}{*}{ 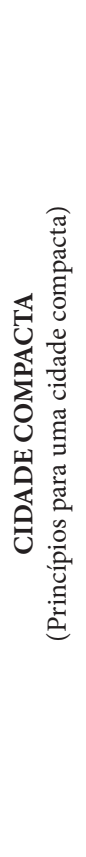 } & Adensamento e otimização das áreas urbanas, criando espaços eficientes e de uso múltiplo. \\
\hline & Limitação da expansão territorial, com eficiência quanto aos usos dos recursos naturais. \\
\hline & Otimização dos sistemas de infraestrutura urbana. \\
\hline & $\begin{array}{l}\text { Várias centralidades na cidade, com multifunções, com criação de empregos, equipamentos } \\
\text { públicos e serviços distribuídos pelos diversos bairros da cidade. }\end{array}$ \\
\hline & $\begin{array}{l}\text { Diversidade cultural e social: integração de pessoas no espaço urbano, com a inclusão } \\
\text { socioespacial. }\end{array}$ \\
\hline & Maior mobilidade e maior Incentivo ao transporte alternativo ( bicicleta, pedestres). \\
\hline & Deve possuir políticas habitacionais no centro. \\
\hline & $\begin{array}{c}\text { Criação de corredores de vegetação que conectem parques e áreas verdes urbanas, evitando } \\
\text { ilhas de calor. }\end{array}$ \\
\hline & Proteção das áreas agrícolas rural-urbanas. \\
\hline & $\begin{array}{c}\text { Concentração dos portadores de informação (membros do governo) e participação popular } \\
\text { nas decisões. }\end{array}$ \\
\hline & $\begin{array}{c}\text { Redução do número de viagens de transportes e consequente redução da emissão de } \\
\text { poluentes. }\end{array}$ \\
\hline
\end{tabular}

Fonte: elaboração própria.

Desses atributos, alguns se referem ao ordenamento espacial da cidade, sendo importante para seu alcance, encontrar nos instrumentos urbanísticos amparo para sua obtenção, quais sejam:

- Garantia de acesso a serviços básicos;

- Reservas de áreas seguras para atividades estratégicas dentro da cidade;

- Adensamento e otimização das áreas urbanas, criando espaços eficientes e de uso múltiplo;

- Limitação da expansão territorial, com eficiência quanto aos usos dos recursos naturais;

- Otimização dos sistemas de infraestrutura urbana;

- Criação de várias centralidades multifuncionais na cidade (empregos, equipamentos públicos e serviços distribuídos pelos diversos bairros da cidade); 
- Diversidade cultural e social: integração de pessoas no espaço urbano, com a inclusão socioespacial;

- Maior mobilidade com uso integrado de transportes públicos, bicicletas e pedestres;

- Atividades habitacionais nos centros urbanos;

- Corredores de vegetação que conectam parques e áreas verdes urbanas;

Assim, seguindo o intuito do estudo, a discussão evolui para verificar como os programas habitacionais têm respondido a esses atributos da habitação sustentável e quais instrumentos urbanísticos podem apoiá-los.

\subsection{Bases normativas da política urbana e da política habitacional}

O que dizer sobre a integração entre política habitacional e urbana? Desde 2001, com a instituição do Estatuto da Cidade, Lei 10.257/2001, regulamentando o artigo 182 da Constituição da República Federativa do Brasil de 1988 (CRFB/1988) que trata da política de desenvolvimento urbano, foram instituídas as diretrizes gerais de ordem pública e interesse social que regulam o uso da propriedade urbana, garantindo, entre outros aspectos, a gestão democrática, o combate à irregularidade fundiária e o combate à especulação imobiliária, onde, para cada problema foram definidos instrumentos para tentar combatê-los (ROLNIK, 2001).

O texto do Estatuto reforça a importância do Plano Diretor ${ }^{8}$ (proposto pela CF 1988), definindo que ele é parte integrante do processo do planejamento municipal (art. 40, $\$ 1^{\circ}$ ) e detalhando a definição de critérios para a obrigatoriedade de elaboração de planos diretores participativos para alguns municípios (art. 41). Obrigatório para cidades com mais de 20 mil habitantes, o Plano Diretor deve assegurar o atendimento das necessidades do cidadão quanto à qualidade de vida, à justiça social e ao desenvolvimento de atividades econômicas. Ele é o instrumento básico da política de desenvolvimento e expansão urbana, que garante a gestão democrática da cidade.

Quanto à Política Nacional de Habitação (PNH), esta foi instituída pelo Ministério das Cidades em 2004, tendo como objetivo principal garantir à população, principalmente para a de baixa renda, o acesso à habitação digna, sendo para tal, indispensável a integração entre a política habitacional e a política nacional de desenvolvimento urbano. A PNH conta com um conjunto de instrumentos criados por meio da Lei $n^{\circ} 11.124 / 2005$, pelos quais se viabiliza a sua implementação, sendo eles: o Sistema Nacional de Habitação - SNH, o Desenvolvimento Institucional, o

8 O Plano Diretor é um instrumento básico da política de desenvolvimento e de expansão urbana (art. 182, parágrafo $1^{\circ}$ ), o qual deve definir princípios, estratégias e instrumentos de ordenamento da cidade, de modo a garantir o cumprimento da função social da propriedade. 
Sistema de Informação, Avaliação e Monitoramento da Habitação e o Plano Nacional de Habitação, que possuem como foco a mobilização de recursos para a viabilização da habitação de interesse social.

Assim, de acordo com a PNH, que buscou integrar a política habitacional com a urbana, o Plano de Habitação do município deve seguir os preceitos definidos no Plano Diretor do município e utilizar os instrumentos previstos no Estatuto da Cidade de forma que consiga atender seus objetivos. Diante do avanço da concepção de sustentabilidade e de sua inserção como objetivo das políticas públicas urbanas era de se esperar mudanças na forma de provimento habitacional. Entretanto, o processo histórico da habitação social brasileira nos remete à produção da moradia no modelo de grandes conjuntos habitacionais, onde, o Estado, por meio de parcerias com a iniciativa privada ou não, os construiu fora da malha urbana consolidada da cidade, na maioria das vezes sem infraestrutura e serviços, cercados de espaços vazios e/ou subutilizados, sem miscigenação de funções, de renda ou culturas (CNM, 2010), o que denota que o objetivo era prover uma edificação.

A título de exemplo de como se mantém essa visão, observa-se que, mesmo após anos de críticas às antigas experiências, o programa habitacional implementado desde 2009 e ainda vigente (Programa Habitacional Minha Casa Minha Vida PMCMV), se coloca à frente contra os preceitos da Política Nacional de Habitação ${ }^{9}$ - PNH, que visa a promoção de habitação adequada e regular, com acesso a serviços públicos, reduzindo a desigualdade social e promovendo a ocupação urbana planejada'. Significa, assim, um retorno de vários paradigmas existentes nos governos populistas do Estado Novo e do Período Militar, com a era do Banco Nacional de Habitação BNH. Essa contradição expõe o fato de não poder negar o desconhecimento ao tema, já que suas mazelas estão expostas nas cidades brasileiras.

Alguns problemas foram visualizados na utilização da legislação habitacional e urbana de vários municípios brasileiros, dificultado o diálogo entre os dois Planos, dentre os quais destacam-se:

(i) Apenas os instrumentos que se referem de forma clara à habitação são previstos nos Planos Diretores, muitas vezes sem aplicação e sem entender a interpelação entre a configuração urbana como um todo no provimento de condições de habitabilidade. De acordo com Pesquisas de Avaliação dos Novos Planos Diretores produzidos, coordenadas pelo sistema CONFEA/CREAs e pelo IPPUR/UFRJ, em parceria com o Ministério das Cidades, estima-se que cerca de $80 \%$ dos Planos Diretores contemplaram a criação de ZEIS, depois de aprovado o Estatuto da Cidade, embora apenas 30\% dos planos regulamentem ZEIS de vazio (Ministério das Cidades, 2009);

(ii) Muitos Planos Diretores e de Política Municipal de Habitação não utilizam os mecanismos de participação da população, o que leva a desconsideração

\footnotetext{
Instituída em 2004 pelo Ministério das Cidades. A PNH considera fundamental para atingir seus objetivos a integração entre a política habitacional e a política nacional de desenvolvimento urbano.
} 
das demandas sociais de habitação que representam o conjunto de necessidades do dia a dia da população (CYMBALISTA, 2007);

(iii) Em várias municipalidades o Planejamento Habitacional é atribuído a um órgão (muitas vezes de orientação a assistência social) e a Política urbana a outro, gerando a não integração entre instrumentos e as demandas urbanas;

(iv) A atribuição da elaboração dos Planos de forma exclusiva à contratação de consultorias externas tende a gerar Planos Diretores que não refletem a cidade real, dificultando a explicitação dentro das necessidades da população e sua implementação pelo poder público (ROLNIK, 2001);

(v) As discrepâncias temporais na elaboração dos Planos de Habitação e Urbano associadas às constantes práticas de prever instrumentos para uma posterior regulamentação;

(vi) Alguns aspectos inerentes à dinâmica urbana que, se não bem conduzidos pela gestão pública, podem comprometer qualquer política bem elaborada tecnicamente, como: os conflitos de interesse dos agentes envolvidos - poder público, população, movimentos populares e empresários. (SOUSA, 2010).

Fatores como esses, favorecem a desarticulação entre a política habitacional e a política urbana, contribuindo para a criação de unidades habitacionais localizadas nas franjas das cidades com as mazelas já referidas.

No sentido de identificar as convergências, foi procedida uma leitura das diretrizes e dos instrumentos que trazem o Estatuto, exposta no quadro 2, para posterior observância em alguns planos diretores e em sua implementação, de modo a verificar sua pertinência em promover a habitação de interesse social.

Quadro 2: Comparação entre as diretrizes gerais e os instrumentos propostos pelo Estatuto da Cidade.

\begin{tabular}{|c|c|}
\hline Diretrizes gerais & $\begin{array}{c}\text { Instrumentos propostos aplicáveis } \\
\text { à realização da diretriz }\end{array}$ \\
\hline $\begin{array}{c}\text { I.Garantia do direito a cidades sustentáveis: } \\
\text { direito à terra urbana, à moradia, ao } \\
\text { saneamento ambiental, à infra-estrutura } \\
\text { urbana, ao transporte e aos serviços públicos, } \\
\text { ao trabalho e ao lazer. }\end{array}$ & $\begin{array}{c}\text { IPTU }^{1} \text {; incentivos e benefícios fiscais e financeiros } \\
\text { desapropriação }{ }^{2} \text {; instituição de zonas especiais de } \\
\text { interesse social; concessão de direito real de uso; } \\
\text { concessão de uso especial para fins de moradia; } \\
\text { usucapião especial de imóvel urbano; regularização } \\
\text { fundiária; assistência técnica e jurídica gratuita para } \\
\text { as comunidades e grupos sociais menos favorecidos; } \\
\text { instituição de unidades de conservação }{ }^{2} .\end{array}$ \\
\hline II. Gestão democrática participativa. & \begin{tabular}{c} 
refendo popular e plebiscito. \\
\hline
\end{tabular} \\
\hline
\end{tabular}




\begin{tabular}{|c|c|}
\hline $\begin{array}{l}\text { III. Cooperação (governos, a iniciativa privada } \\
\text { e sociedade). }\end{array}$ & \\
\hline $\begin{array}{l}\text { IV. Planejamento do desenvolvimento das } \\
\text { ciudades. }\end{array}$ & $\begin{array}{c}\text { Plano diretor }{ }^{2} \text {; disciplina do parcelamento, do uso e } \\
\text { da ocupação do solo }{ }^{2} \text { zoneamento ambiental; EIA } \\
\text { e EIV }{ }^{2} \text {. }\end{array}$ \\
\hline $\begin{array}{l}\text { V. Oferta de equipamentos urbanos e } \\
\text { comunitários, transporte e serviços públicos. }\end{array}$ & $\begin{array}{l}\text { Plano diretor; disciplina do parcelamento, do uso e } \\
\text { da ocupação do solo; desapropriação; instituição de } \\
\text { unidades de conservação. }\end{array}$ \\
\hline $\begin{array}{l}\text { VI. Ordenação e controle do uso do solo, de } \\
\text { forma a evitar: } \\
\text { a utilização inadequada dos imóveis urbanos; } \\
\text { a proximidade de usos incompatíveis ou } \\
\text { inconvenientes; o parcelamento do solo, a } \\
\text { edificação ou o uso excessivos ou inadequados } \\
\text { em relação à infra-estrutura urbana; } \\
\text { a instalação de empreendimentos ou } \\
\text { atividades que possam funcionar como pólos } \\
\text { geradores de tráfego, sem a previsão da infra- } \\
\text { estrutura correspondente; } \\
\text { a retenção especulativa de imóvel urbano, que } \\
\text { resulte na sua subutilização ou não utilização; } \\
\text { a deterioração das áreas urbanizadas; } \\
\text { a poluição e a degradação ambiental. }\end{array}$ & $\begin{array}{l}\text { Plano diretor }{ }^{2} \text {; disciplina do parcelamento, do uso } \\
\text { e da ocupação do solo }{ }^{2} \text {; zoneamento ambiental }{ }^{2} \text {; } \\
\text { desapropriação }{ }^{1} \text {; tombamento de imóveis ou de } \\
\text { mobiliário urbano; parcelamento, edificação ou } \\
\text { utilização compulsórios; direito de preempção; } \\
\text { operações urbanas consorciadas; EIA }{ }^{2} \text { e EIV. }\end{array}$ \\
\hline $\begin{array}{l}\text { VII - Integração e complementaridade entre } \\
\text { as atividades urbanas e rurais. }\end{array}$ & $\begin{array}{l}\text { Plano diretor; disciplina do parcelamento, do uso e } \\
\text { da ocupação do solo. }\end{array}$ \\
\hline $\begin{array}{l}\text { IX - Justa distribuição dos benefícios e ônus } \\
\text { decorrentes do processo de urbanização. }\end{array}$ & $\begin{array}{l}\text { Plano plurianual; diretrizes orçamentárias e } \\
\text { orçamento anual; gestão orçamentária participativa; } \\
\text { planos de desenvolvimento econômico e social; } \\
\text { IPTU; contribuição de melhoria; incentivos e } \\
\text { benefícios fiscais e financeiros; } \\
\text { instituição de zonas especiais de interesse social; } \\
\text { concessão de direito real de uso; concessão de uso } \\
\text { especial para fins de moradia; usucapião especial } \\
\text { de imóvel urbano; direito de superfície; outorga } \\
\text { onerosa do direito de construir e de alteração de uso; } \\
\text { regularização fundiária. }\end{array}$ \\
\hline $\begin{array}{l}\text { X - Adequação dos instrumentos de política } \\
\text { econômica, tributária e financeira e dos gastos } \\
\text { públicos aos objetivos do desenvolvimento } \\
\text { urbano, de modo a privilegiar os } \\
\text { investimentos geradores de bem-estar geral e } \\
\text { a fruição dos bens pelos diferentes segmentos } \\
\text { sociais. }\end{array}$ & $\begin{array}{l}\text { Plano plurianual; diretrizes orçamentárias e } \\
\text { orçamento anual; gestão orçamentária participativa; } \\
\text { planos de desenvolvimento econômico e social; } \\
\text { IPTU; contribuição de melhoria; incentivos e } \\
\text { benefícios fiscais e financeiros. }\end{array}$ \\
\hline
\end{tabular}




\begin{tabular}{|c|c|}
\hline $\begin{array}{l}\text { XI - Recuperação dos investimentos do Poder } \\
\text { Público de que tenha resultado a valorização } \\
\text { de imóveis urbanos. }\end{array}$ & $\begin{array}{c}\text { Plano plurianual; diretrizes orçamentárias e } \\
\text { orçamento anual; gestão orçamentária participativa; } \\
\text { planos de desenvolvimento econômico e social; } \\
\text { IPTU; contribuição de melhoria. } \\
\text { Direito de preempção; outorga onerosa do direito de } \\
\text { construir e de alteração de uso; operações urbanas } \\
\text { consorciadas. }\end{array}$ \\
\hline $\begin{array}{c}\text { XII - Proteção, preservação e recuperação } \\
\text { do meio ambiente natural e construído, do } \\
\text { patrimônio cultural, histórico, artístico, } \\
\text { paisagístico e arqueológico. }\end{array}$ & $\begin{array}{l}\text { Plano diretor²; disciplina do parcelamento, do uso } \\
\text { e da ocupação do solo } ; \text { zoneamento ambiental'; } \\
\text { incentivos e benefícios fiscais e financeiros }{ }^{1} \text {. } \\
\text { Tombamento de imóveis ou de mobiliário } \\
\text { urbano; instituição de unidades de conservação } \\
\text { transferência do direito de construir; } \text { EIA }^{2} \text { e EIV }^{2} \text {. }\end{array}$ \\
\hline $\begin{array}{l}\text { XIII - Audiência do Poder Público municipal } \\
\text { e da população interessada nos processos } \\
\text { de implantação de empreendimentos ou } \\
\text { atividades com efeitos potencialmente } \\
\text { negativos sobre o meio ambiente natural ou } \\
\text { construído, o conforto ou a segurança da } \\
\text { população. }\end{array}$ & $\begin{array}{l}\text { Plano plurianual; diretrizes orçamentárias e } \\
\text { orçamento anual; gestão orçamentária participativa; } \\
\text { planos de desenvolvimento econômico e social; } \\
\text { referendo popular e plebiscito. }\end{array}$ \\
\hline $\begin{array}{l}\text { XIV - Regularização fundiária e urbanização } \\
\text { de áreas ocupadas por população de baixa } \\
\text { renda mediante o e estabelecimento de } \\
\text { normas especiais de urbanização, uso e } \\
\text { ocupação do solo e edificação, consideradas } \\
\text { a situação socioeconômica da população e as } \\
\text { normas ambientais. }\end{array}$ & $\begin{array}{l}\text { Plano diretor; disciplina do parcelamento, do uso e } \\
\text { da ocupação do solo. } \\
\text { Desapropriação; instituição de zonas especiais de } \\
\text { interesse social; concessão de direito real de uso; } \\
\text { concessão de uso especial para fins de moradia; } \\
\text { usucapião especial de imóvel urbano; regularização } \\
\text { fundiária; assistência técnica e jurídica gratuita para } \\
\text { as comunidades e grupos sociais menos favorecidos. }\end{array}$ \\
\hline $\begin{array}{l}\text { XV - Simplificação da legislação de } \\
\text { parcelamento, uso e ocupação do solo e das } \\
\text { normas edilícias, com vistas a permitir a } \\
\text { redução dos custos e o aumento da oferta dos } \\
\text { lotes e unidades habitacionais. }\end{array}$ & $\begin{array}{l}\text { Plano diretor; disciplina do parcelamento, do uso e } \\
\text { da ocupação do solo; }\end{array}$ \\
\hline $\begin{array}{c}\text { XVI - Isonomia de condições para os } \\
\text { agentes públicos e privados na promoção de } \\
\text { empreendimentos e atividades relativos ao } \\
\text { processo de urbanização, atendido o interesse } \\
\text { social. }\end{array}$ & $\begin{array}{l}\text { Plano diretor; disciplina do parcelamento, do uso } \\
\text { e da ocupação do solo; IPTU; contribuição de } \\
\text { melhoria; incentivos e benefícios fiscais e financeiros; } \\
\text { direito de superfície; transferência do direito de } \\
\text { construir; operações urbanas consorciadas. }\end{array}$ \\
\hline
\end{tabular}

Fonte: Elaboração própria.

\section{Nota:}

(1) - Instrumentos propostos que têm potencial de aplicação para o controle do uso e ocupação do solo visando a proteção ambiental, mas que efetivamente não são utilizados pelos municípios para a gestão ambiental urbana.

(2) - Instrumentos propostos que são plenamente aplicáveis ao controle do uso e ocupação do solo visando a proteção ambiental. 


\subsection{Instrumentos urbanísticos previstos na política urbana e suas relações com o provimento da habitação sustentável}

Os instrumentos que contemplam o Estatuto da Cidade auxiliam na regulamentação urbana para alcance das várias dimensões que o conceito de sustentabilidade suscita. Assim, pode-se inferir que, ao introduzir o direito à moradia em seu Art. $2^{\circ}$, não estaria falando apenas do exclusivo acesso à casa própria, mas sim, que a moradia seja um dos elementos indispensáveis para o direito à cidade sustentável, asseguradas as necessidades das pessoas referenciadas na qualidade de vida e na justiça social (RAMOS, 2011). É certo que essa visão significa um grande avanço sobre o que se considerava antes a cidade, mas deve levar em conta que no Estatuto a visão de sustentabilidade ambiental ainda é reduzida, dado que sua ênfase está na sustentabilidade social (BEZERRA e RIBAS, 2004). Existe, assim, um processo de aprimoramento rumo à sustentabilidade socioambiental.

A aplicabilidade desses instrumentos pode ser encontrada em vários estudos elaborados no sentido de divulgar, analisar e/ou criticar sua adoção dos quais, foram utilizados: Cymbalista (2007); Ribas (2003); e Ministério das Cidades (2005). O Ministério das Cidades também desenvolveu vários manuais sobre os instrumentos, disponíveis em seu sítio, para apoio aos municípios na elaboração de Planos Diretores. Tendo em conta essa base de informações e com apoio na experiência com alguns planos diretores foi possível realizar um exercício de correlacionar os atributos espaciais que favorecem a habitação sustentável (constantes do item 3) e os instrumentos acima referidos, para identificar aqueles que podem ser qualificados como promotores de uma habitação sustentável. Ver quadro 3.

Quadro 3: Relação entre atributos e instrumentos para promoção de habitações sustentáveis.

\begin{tabular}{|c|c|}
\hline \multicolumn{2}{|c|}{$\begin{array}{l}\text { Relação entre atributos e instrumentos para promoção } \\
\text { de moradias sustentáveis }\end{array}$} \\
\hline Atributos & Instrumentos \\
\hline Garantia a todos de acesso a serviços básicos. & $\begin{array}{l}\text { Plano de desenvolvimento } \\
\text { econômico e social. }\end{array}$ \\
\hline $\begin{array}{l}\text { Reserva de áreas seguras para atividades estratégicas dentro } \\
\text { da cidade. }\end{array}$ & LUOS, ZEE. \\
\hline $\begin{array}{l}\text { Limitação da expansão territorial, com eficiência quanto aos } \\
\text { usos dos recursos naturais. }\end{array}$ & \multirow{3}{*}{ ZEE, LUOS, PDOT } \\
\hline $\begin{array}{l}\text { Criação de corredores de vegetação que conectam parques e } \\
\text { áreas verdes urbanas. }\end{array}$ & \\
\hline $\begin{array}{c}\text { Adensamento e otimização das áreas urbanas, criando espaços } \\
\text { eficientes e de uso múltiplo. }\end{array}$ & \\
\hline
\end{tabular}




\begin{tabular}{|c|c|}
\hline $\begin{array}{l}\text { Diversidade cultural e social: Integração de pessoas no espaço } \\
\text { urbano, com a inclusão socioespacial }\end{array}$ & $\begin{array}{l}\text { LUOS, ZEIS, Desapropriação, Direi- } \\
\text { to de Preempção. }\end{array}$ \\
\hline $\begin{array}{l}\text { Maior mobilidade com uso integrado de transportes públicos, } \\
\text { bicicletas e pedestres. }\end{array}$ & EIV, ZEIS, OUC. \\
\hline Atividades habitacionais nos centros urbanos. & \multirow{3}{*}{$\begin{array}{l}\text { Operações Urbanas Consorciadas, } \\
\text { ZEIS, Direito de Preempção, IPTU } \\
\text { progressivo, ODIR. }\end{array}$} \\
\hline $\begin{array}{c}\text { Criação de várias centralidades multifuncionais na cidade } \\
\text { (empregos, equipamentos públicos e serviços distribuídos } \\
\text { pelos diversos bairros da cidade). }\end{array}$ & \\
\hline Otimização dos sistemas de infraestrutura urbana. & \\
\hline
\end{tabular}

Fonte: Elaboração própria.

Quanto à concepção e possibilidade de uso de três desses instrumentos, podem-se identificar casos particulares de sua adoção com vistas ao provimento da habitação. Eles vêm como uma tentativa de articular diretrizes de política urbana para tomada de decisões de política habitacional. Os instrumentos estudados são: (i) Zona Especial de Interesse social - ZEIS de vazio; (ii) Operação Urbana Consorciada; e (iii) Outorga Onerosa do Direito de Construir, para fins de promoção de programas habitacionais.

As ZEIS de vazio são capazes de permitir habitações sociais em áreas mais centrais e melhor localizadas na cidade, dotadas de infraestrutura urbana essencial para a população. Permite uma antecipação de reserva de área evitando que no futuro sua ocupação se torne proibitiva do ponto de vista econômico; já as OUC trabalham com a possibilidade de modificação de índices e características do uso e ocupação do solo, com alterações edilícias e a concessão de incentivos para as operações que visem a constituição de um tecido urbano de mix social e a redução de impactos ambientais; e as OODC visam estabelecer áreas para aumento do coeficiente de aproveitamento básico, mediante contrapartida do beneficiário, considerando a infraestrutura da área e o aumento da densidade esperada, possibilitando incentivos para a habitação social. A questão, porém, é: como aplicar esses instrumentos de forma eficiente para a cidade?

Esses instrumentos possuem suas características em separado, mas podem ser utilizados em conjunto, potencializando os atributos nas áreas onde serão alocados programas habitacionais. A título de exemplo de como esses instrumentos melhor poderiam ser utilizados para gerar atributos de sustentabilidade na estrutura urbana, se apontam alguns critérios, como:

- (1) ZEIS de vazio: (a) as áreas devem dispor de infraestrutura e equipamentos públicos adequados; (b) as áreas devem ser de fácil integração ao sistema viário de seu entorno e possuírem certa centralidade dentro da estrutura urbana; (c) devem possuir segurança geológica e geotécnica e evitar impactos em áreas ambientais sensíveis; (d) garantir diversidade de usos, com variedade nas formas e 
dimensões do parcelamento que possibilitem um mix social; (e) estar conectada ao sistema de transporte púbico; (f) possuir flexibilidade na determinação de regras de parcelamento, uso e ocupação do solo; e (g) estabelecer porcentagem mínima destinada à habitação de interesse social - HIS, variando de 70 a $80 \%$.

Para maior efetividade esses critérios podem ser objeto de prévia avaliação, utilizando alguns métodos e/ou indicadores para sua avaliação, quais sejam: (i) Índice de qualidade de vida urbana - IQVU, composto por indicadores que qualificam o território em termos de acesso à serviços, meio ambiente, infraestrutura, equipamentos e segurança; (ii) avaliação da inserção urbana; e (iii) distribuição de equipamentos públicos e de lazer.

- (2) No caso da OUC, existem outros aspectos a serem avaliados para sua adoção, de modo a obter o êxito de integrar a habitação a uma área de requalificação urbana, como: (a) definição clara do polígono de sua aplicação, bem como as transformações requeridas pela dinâmica urbana, de modo que, o projeto da área seja assertivo em ocupar o novo espaço com as melhorias socioambientais necessárias; (b) definição de mecanismos urbanísticos que orientem a ação do mercado produtor imobiliário na direção do desenvolvimento urbano pretendido; (c) definir estoque de potencial adicional de construção reservado e vinculado à unidade habitacional de interesse social; (d) novos padrões urbanísticos em consonância com a previsão do mix de rendas a ser atendido; e (e) aumento do potencial construtivo do lote, coeficiente de aproveitamento e/ ou mudanças de uso de seus terrenos de modo a viabilizar os capitais privados e atender aos objetivos do planejamento.

Ao considerar que podem ser utilizados para todas as atividades urbanas, destaca-se que, em relação às áreas de habitações, se deve ter em conta os atributos já referidos para habitação sustentável, como: (i) prever a proximidade das redes de transportes, centros de compras e serviços, equipamentos educacionais e de lazer e locais com concentração de empregos; (ii) aplicação da cota máxima de coeficiente, que pode vir acompanhado de uma diversificação das dimensões das unidades, resultando numa variedade de produtos formatados para diferentes públicos; e (iii) adensamento populacional com diversidade de renda.

O sucesso da operação é dado pelo volume de recursos que ela gera e pela quantidade de infraestrutura que ela é capaz de implantar com os recursos obtidos por meio da venda de Certificados de Potencial Adicional de Construção - CEPAC. Esses por sua vez decorrem das exceções à Lei de Uso e Ocupação do Solo- LUOS, concedidas pelo poder municipal, que deve utilizar essa arrecadação para investir em ações de estruturação, configuração, qualificação e 
melhoria urbana das áreas definidas para atuação da OUC, segundo um planejamento previamente aprovado.

Como uma parceria público-privada, sua gestão deve se pautar por alguns critérios como: (i) fugir da armadilha arrecadatória e da lógica tributarista e/ou especulativa que muitas vezes acabam se sobrepondo às decisões e interesses públicos; (ii) garantir a recuperação e distribuição da mais-valia gerada pelo próprio investimento público e, assim, regular distorções de valorização fundiária e/ou imobiliária geradas por esses mesmos investimentos; e (iii) promover, sob controle social, formas de ocupação mais intensa, qualificada e inclusiva do espaço urbano, articuladas à medida que racionalizem e democratizem a utilização das redes de infraestrutura e o acesso a equipamentos sociais, inclusive solo urbanizado, habitação e meio ambiente.

- (3) As OODC adotadas nos Planos Diretores podem ser voltadas à promoção da habitação sustentável desde que considere alguns aspectos, como: (a) lei de zoneamento, indicando as zonas que poderão ser aplicados o uso acima do coeficiente único, considerando a infraestrutura existente; (b) possibilidade de o particular transferir o seu direito de construir não utilizado até o limite do coeficiente único; e (c) a manutenção da proporção entre os solos públicos e privados, constituindo na concessão onerosa acima do coeficiente único por meio de doação de áreas ao poder público ou do equivalente em dinheiro.

O instrumento visa o controle do adensamento pelo poder público e que esse, quando ocorra, se dê nos termos do interesse coletivo e com a restauração do equilíbrio entre imóveis de uso público e uso privado. A outorga não precisa, necessariamente, ser aplicada na zona objeto da própria outorga e, nesse sentido, a sua onerosidade possibilita a redistribuição das mais valias do processo de urbanização das cidades, permite a recomposição do equilíbrio de áreas de uso público e particular, possibilita a sustentabilidade das cidades, o controle da densidade construtiva, promove a redistribuição das oportunidades imobiliárias na cidade e contribui para o combate da especulação imobiliária. (OLIVEIRA, 2015).

Para a adoção de qualquer um desses instrumentos, é necessário que eles estejam definidos no Plano Diretor do Município, que é o direcionador da política de desenvolvimento urbano a ser adotada, no qual serão definidos os parâmetros indispensáveis à sua aplicação. 


\section{Discussão e resultados}

Para cada um dos instrumentos destacado foi estudado um exemplo de sua aplicação com o intuito de observar a eficiência de seu emprego no que tange ao objetivo de propiciar uma localização habitacional que atenda aos atributos de sustentabilidade urbana. Para as ZEIS de vazio, foi utilizado o caso do Distrito Federal, para a OUC foi empregado o caso de São Paulo e para as OODC foi analisado o exemplo de Palmas.

\subsection{Adoção da ZEIS de vazio no Distrito Federal.}

No Plano Diretor de Ordenamento Territorial (PDOT) do DF, foram selecionadas 13 áreas ${ }^{10}$ ainda não ocupadas, distribuídas por diferentes regiões do Distrito Federal, com capacidade para atendimento de aproximadamente 105 mil famílias, conforme Figura 1 (SEGETH, 2017).

Figura 1: Mapa com as áreas definidas para Regularização Fundiária (PDOT) e Oferta de Áreas Habitacionais no DF.

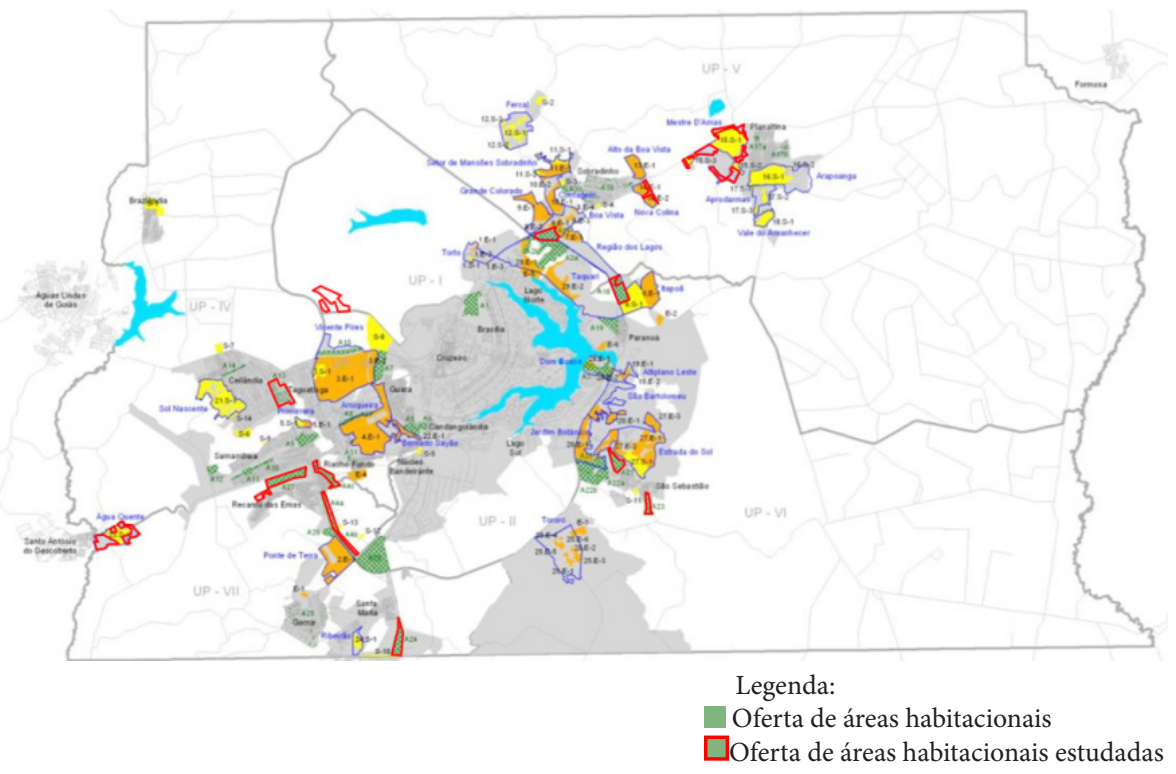

Fonte: PDOT. 2009.

\footnotetext{
10 As áreas selecionadas no Caderno de ZEIS da SEGETH são: Áreas Livres QNJ Taguatinga (RAIII); Áreas Livres Água Quente (RA XV); Áreas Livres Nova Colina (RA V); Área DER (RA V); Áreas Livres Mestre D'armas Grotão (RA VI); Cana do Reino I (RA XXX); Cana do Reino II ( RA XXX); Quadras 9, 11, 13 e 15 (RA XVII); Vargem da Benção Qd. 117 e 118 ( RAXV); QNR 06 (RA IX); Etapa 3 Riacho Fundo II (RAXXI); Vargem da Benção (RAXVI) e Setor Meireles (RAXIII).
} 
As diferentes poligonais destinadas à habitação pelo PDOT foram avaliadas segundo os atributos identificados como propícios à localização habitacional sustentável, como: (i) proximidade com o tecido urbano já existente; (ii) presença de infraestrutura; e (iii) proximidade de centralidades urbanas, ou seja, que tenham acesso a empregos e serviços. Utilizou-se um mapeamento de conectividade para essa avaliação onde foi observado que, das 13 áreas estudadas, apenas uma delas possui os atributos acima citados e será denominada de área "integrada à estrutura urbana consolidada”. Três outras áreas podem ser consideradas significativamente integradas, 5 áreas são significativamente segregadas e 6 áreas são segregadas (SEGETH, 2017). De acordo com a Figura 2, observa como exemplo as áreas: Cana do Reino I (Região Administrativa - RA Vicente Pires), Crixá (RA São Sebastião), Etapa 4 do Riacho Fundo (RA Riacho Fundo II) e Áreas Livres QNJ de Taguatinga (RA Taguatinga).

Figura 2: Mapa de conectividade de alguns exemplos das áreas estudadas para habitação de interesse social.

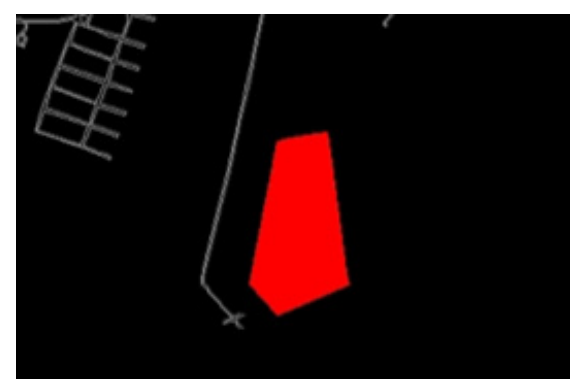

Cana do Reino 1 - RA XXX - Vicente Pires (segregada)

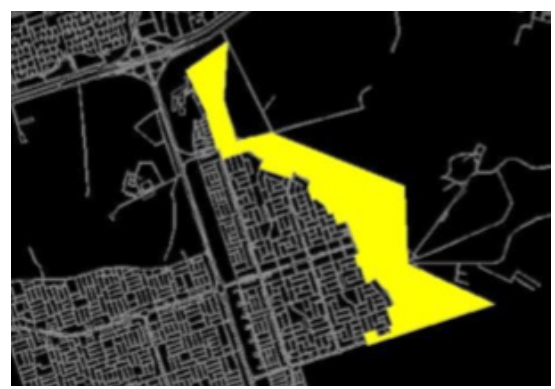

Etapa 4 Riacho Fundo II - RA XXI Riacho Fundo II (significativamente integrada)

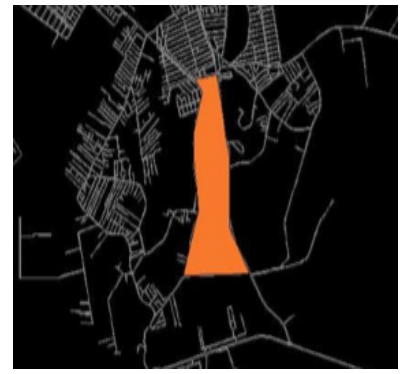

Crixá - RA XIV São Sebastião (significativamente segregada)

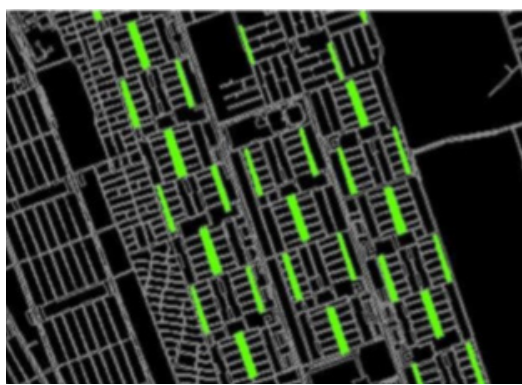

Áreas Livres QNJ - RA III Taguatinga (integrada)

Fonte: Caderno ZEIS SEGETH, 2017.

O conjunto das 13 áreas resultou de pouca efetividade para utilização na alocação dos programas habitacionais devido a evidente falta de aptidão de muitas delas. Novos estudos para demarcação de ZEIS vazias foram procedidos pelo Governo do Distrito 
Federal - GDF. Assim, quando da definição de áreas para o Programa Habitacional Habita Brasília, foram selecionadas mais 8 áreas ${ }^{11}$, visualizadas na Figura 3. Utilizando os mesmos critérios de avaliação anteriores pode-se afirmar que dessas, 5 áreas são integradas e 3 áreas relativamente integradas. Vale destacar que, como o Distrito Federal possui muitas áreas de fragilidade ambiental, essas áreas consideraram para sua definição as diretrizes do Zoneamento Econômico Ecológico - ZEE, ponderando tanto a diversificação produtiva quanto os condicionantes ambientais (Figura 3).

Figura 3: Mapa de conectividade. Exemplo das áreas do Habita Brasília para criação de ZEIS de vazios.

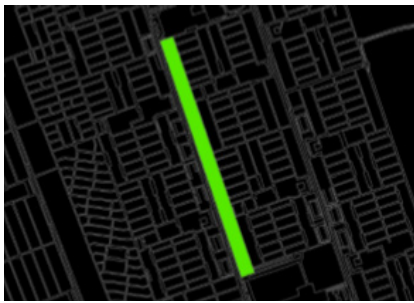

QNL Taguatinga - RAIII Taguatinga (CONECTADA)

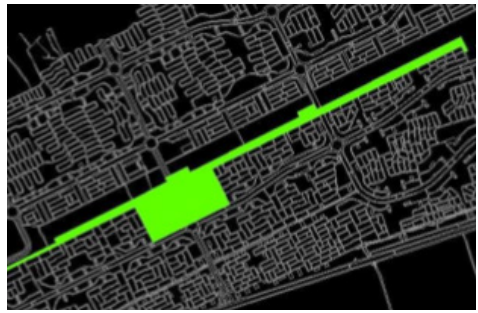

Quadras 100 ímpares - RA XII Samambaia (CONECTADA)

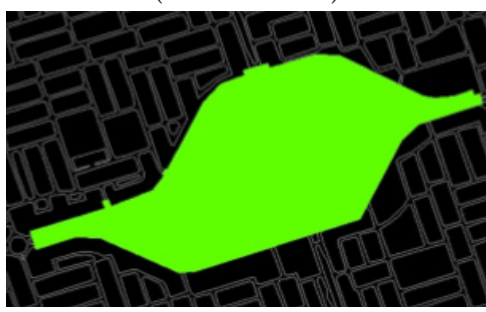

Subcentro Recanto das Emas RA XV Recanto das Emas (CONECTADA)

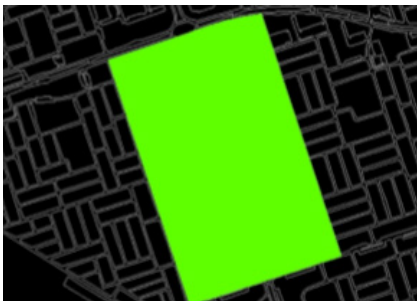

Subcentro Recanto das Emas RA XV Recanto das Emas (CONECTADA)

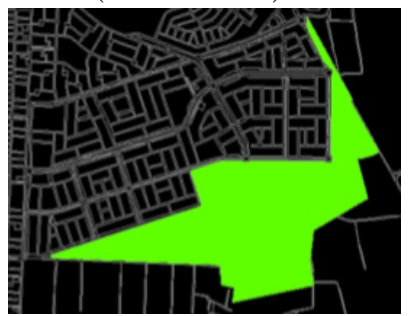

Residencial Pipiripau - RA VI Planaltina (CONECTADA)

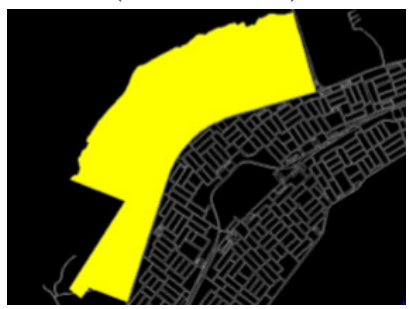

Vargem da Benção - RA XV Recanto das Emas (SIGNIFICATIVAMENTE CONECTADA)

\footnotetext{
11 Áreas do Habita Brasília selecionadas no Caderno de ZEIS da SEGETH são: QNL Taguatinga - RAIII; Vargem da Benção - RA XV; Quadras ímpares - RA XII; Residencial Pipiripau - RA VI; Centro Urbano Recanto das Emas - RA XV e Quadras 19 e 20 de Sobradinho - RA V.
} 


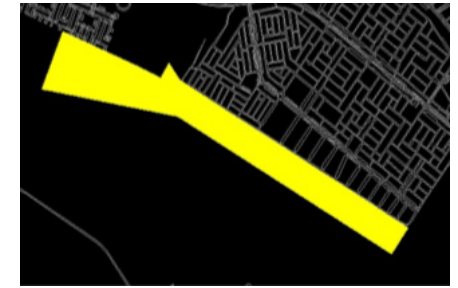

Bonsucesso - RA XIV São Sebastião (SIGNIFICATIVAMENTE CONECTADA)

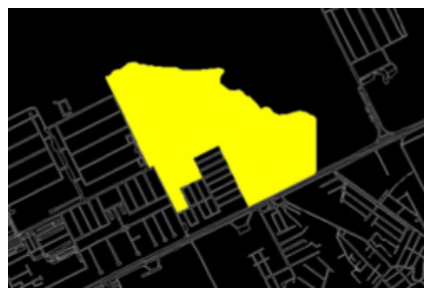

Quadras 19 e 20 de Sobradinho - RA V Sobradinho (SIGNIFICATIVAMENTE CONECTADA)

Fonte: Caderno ZEIS SEGETH, 2017.

A preocupação quanto à conectividade das áreas é essencial para o combate à exclusão social. A falta de integração ao tecido urbano constituído dificulta o acesso a serviços básicos para a população, como infraestrutura de transporte e abastecimento e rede de serviços públicos essenciais.

Mesmo no caso daquelas que foram consideradas conectadas, elas o são ao observar as cidades já existentes, mas em relação ao emprego que se concentra no Plano Piloto e ao mix social, isso não ocorre, devido a uma característica marcante do Distrito Federal que é a segregação sócio espacial. Assim, apesar da tentativa de melhoria da conectividade, buscando áreas mais centralizadas, o caso de criação de ZEIS de vazio no DF esbarra com o problema do espraiamento das cidades e a blindagem do Plano Piloto para com as camadas mais pobres da população. Sendo assim, a busca da habitação mais sustentável, no caso do DF, exige um repensar de seu processo de concentração de empregos e não será uma tarefa exclusiva de um instrumento de ordenamento territorial.

\subsection{Operações Urbanas Consorciadas (OUC) no município de São Paulo}

Em São Paulo, foi estudado o caso da Operação Urbana Centro que tinha o objetivo de repovoar e requalificar o centro por meio do adensamento habitacional, com a transformação dos imóveis abandonados ou subutilizados, ao mesmo tempo em que seria introduzido melhoria na mobilidade urbana e criação de uma rede de espaços públicos adequados a moradores locais. Para tal, previu uma alteração de $10 \%$ a mais no coeficiente de aproveitamento aos empreendimentos resultantes de remembramento de terrenos, em determinadas áreas, de forma a gerar recursos para adequações voltadas à habitação. Essa decisão acabou favorecendo a demolição e a intervenção das edificações ao invés da requalificação e da conservação das características existentes na ocupação urbana, gerando o aumento do valor dos imóveis da região e a expulsão dos poucos moradores da área.

Assim, apesar do exemplo da OUC em São Paulo ter adotado alguns dos critérios necessários para que se alcance localização habitacional considerada 
sustentável, outros critérios não foram observados, como: (i) ausência de produtos formatados para públicos de várias classes sociais; (ii) associação entre o projeto urbano e a gestão; e (iii) otimização do uso das redes de transporte coletivo. Esses fatores interferiram no êxito do objetivo de atendimento dos interesses sociais.

Verifica-se que a requalificação não garante a inclusão social, mesmo que apresente alguns de seus objetivos. Apesar de tornar a inclusão no processo mais provável. É necessário, para tal, um procedimento de gestão permanente, focado nos objetivos inicias.

\subsection{Exemplo de Outorga Onerosa do Direito de Construir (OODC) em Palmas}

Em Palmas, de acordo com o Plano Diretor - LC n²155/2007, foi estabelecido a OODC com a possibilidade de: (i) utilizar um coeficiente de aproveitamento maior, variável conforme a zona de uso, mediante contrapartida financeira; e (ii) definir um estoque de potencial construtivo para cada setor com base na infraestrutura existente e no aumento da densidade. A contrapartida financeira pode ser empregada em qualquer região da cidade, desde que utilizada para projetos de regularização fundiária, habitação de interesse social, reserva de terras, áreas de interesse ambiental, dentre outras, ou ser revertida por meio de bens ou serviços (Ministério das Cidades, 2005).

Entretanto, a avaliação constatou que, por várias omissões da legislação da OODC de Palmas, a definição dos estoques não segue nenhuma relação com a infraestrutura existente nas áreas, mas sim, a delimitação dos limites máximos permitidos para os lotes constante na legislação. Isso leva à possibilidade do uso indiscriminado do instrumento que, ao não ser controlado pelo poder público, tem levado a problemas de infraestrutura, de mobilidade e de falta de equipamentos urbanos, afetando assim, a qualidade de vida da população (PAZ, 2017).

É importante levar em consideração que Palmas, sendo uma cidade ainda com bastante área disponível para construção, talvez esse instrumento não seja o mais apropriado, pois, ao invés de ser utilizado em terrenos subutilizados para adensamento de áreas centrais, apenas resulta na verticalização dos edifícios, provocando sobrecarga para a infraestrutura da cidade e manutenção dos vazios urbanos, que podem se tornar ainda objeto de especulação imobiliária (PAZ, 2017). O que ocorreu de fato foi que a OODC gerou um resultado contrário, favorecendo a especulação imobiliária em detrimento do adensamento populacional, trazendo impactos territoriais consideráveis e influenciando na busca da sustentabilidade.

Observa-se que algumas condições necessárias para utilização da OODC não foram adotadas, dentre elas: (i) a fixação de um coeficiente de aproveitamento único; (ii) a indicação das zonas que poderão trabalhar acima do coeficiente único, considerando a infraestrutura existente; (iii) a transferência do seu direito de construir não utilizado; e (iv) a manutenção da proporção entre o solo público e 
privado, constituindo na concessão onerosa acima do coeficiente único, resultando em futuros problemas com a especulação imobiliária e com a infraestrutura devido ao adensamento em determinados locais.

\section{Considerações finais}

A discussão sobre as características e condições de provimento de habitação sustentável visa corrigir algumas práticas dos programas habitacionais no país que levou à segregação socioespacial nas cidades. A sustentabilidade da habitação estabelece uma relação entre atributos da cidade que condicionam a moradia, como: densidades de média a alta; diversidade de usos nas diferentes zonas urbanas; proximidade casa/ trabalho; localização e provimento dos equipamentos públicos de serviço e de lazer e políticas que priorize os transportes públicos e ativos e outros atributos estudados no artigo. Assim, como se vê, é uma questão de planejamento urbano e remete à necessária integração entre política urbana e política habitacional.

A habitação sustentável tem na localização dentro da estrutura urbana um dos mais relevantes atributos para seu alcance, o que leva à necessária articulação entre política urbana e seus instrumentos de gestão e as decisões de política habitacional. $\mathrm{O}$ estudo de instrumentos previstos no Estatuto da Cidade indica que muitos deles podem ser utilizados nesse sentido, com ênfase para aqueles de caráter negocial ou estratégicos, que vão além dos tradicionais zoneamentos de uso e ocupação do solo. Aliás, esse foi o avanço do Estatuto, dispor de instrumentos de coordenação/ articulação para fins de gestão urbana, antes restritos ao controle.

Os estudos de três desses instrumentos: ZEIS de vazio, a OUC e a OODC indicaram que esses podem levar à constituição e/ou correção de tecidos urbanos mais sustentáveis desde que atendidos os critérios identificados. Entretanto, os estudos procedidos para analisar como esses instrumentos estão sendo adotados no país, tomando como amostra três cidades: Brasília, São Paulo e Palmas, mostrou um quadro preocupante onde, em nenhuma das situações, os objetivos pretendidos foram alcançados. Nos casos da OUC e OODC o estudo mostrou que, pelo contrário, sua aplicação vem favorecendo a especulação imobiliária e não a sustentabilidade que se pretende alcançar. No caso do Distrito Federal é possível que os critérios definidos para o estabelecimento de ZEIS de vazio não tenha obtido o êxito esperado devido ao contexto estrutural da própria formação do DF.

Por fim, fica evidente no estudo que há caminhos e instrumentos para "mudar a cidade", mas faz-se imprescindível o controle social qualificado com as devidas informações técnicas sobre as ações de planejamento e a gestão urbana. 


\section{Referências}

BEZERRA, Maria C. L. A Contribuição da Gestão de Projetos Urbanos Contemporâneos para a Sustentabilidade Ambiental Urbana In: Gestão Urbana e Sustentabilidade. São Paulo: Editora Manolo, v.1, p. 500-535, 2018.

BEZERRA, Maria C. L. e RIBAS, Otto. T. O Desafio da Gestão Ambiental Urbana conceitos e instrumentos. In: SEMINÁRIO INTERNACIONAL SOBRE GESTÃO AMBIENTAL URBANA - EXPERIÊNCIAS E PERSPECTIVAS. Anais [...] NEUR CEAM, Universidade de Brasília, Brasília, 2004.

BRASIL, Presidência da República. Casa Civil. Subchefia para Assuntos Jurídicos. Constituição da República Federativa do Brasil de 1988. Brasília: 1988.

BRASIL, Ministério das Cidades. Política Nacional de Habitação. Caderno MCidades 4. Brasília: 2005.

BRASIL, Amíria Bezerra. A ineficácia das ZEIS: um problema de legislação ou uma questão político-social? O caso de Fortaleza. 2016. 260p. Tese (Doutorado) em Arquitetura e Urbanismo, Área de concentração: Habitat. FAU/USP. São Paulo.

CARVALHO, L.; CARRASCO, U; FARINHA, Manuel; BATISTA, Sandra; FERNANDES, José Miguel; SOUZA, Guilherme; LEITÃO, Numo. Risco, desastre e resiliência - um desafio para a cidade da Amadora. IX CONGRESSO DA GEOGRAFIA PORTUGUESA; Anais [...]Universidade de Évora, Novembro, 2013.

Confederação Nacional de Municípios - CNM. Política Nacional de Habitação: O atual cenário das políticas do setor habitacional e suas implicações para os municípios brasileiros. Estudos técnicos. Volume 13. Brasília: 2010.

COSTA, H.S.M. Desenvolvimento urbano sustentável: uma contradição de termos? Instituto de Geociências, UFMG. Belo Horizonte: 2013.

COSTA, N. M. S. M. da. Mobilidade e Transporte em Áreas Urbanas. Tese (Doutorado) - Faculdade de Geografia de Lisboa. Universidade de Lisboa, 2007.

CYMBALISTA, Renato. Instrumentos de planejamento e gestão da política urbana: um bom momento para uma avaliação. In: BUENO, Laura M.; CYMBALISTA, Renato (Org.). Planos diretores municipais: novos conceitos de planejamento territorial. São Paulo: Anna Blume: Instituto Pólis: PUCCAMP, 2007, p. 25-32.

GOMES, J. C. F. A Mobilidade e a Teoria da Cidade Compacta - Caso Estudo: A cidade de Lisboa. Dissertação (Mestrado) - Universidade Técnica de Lisboa, Lisboa, 2009.

JENKS, M.; Burton, E.; Williams K. (Ed.). The compact city: A sustainable urban form? London: Chapman and Hall, 1996. 
JACOBS, J. Morte e Vida de Grandes Cidades. 2. ed. São Paulo: Editora WMF, Martins Fontes, 2009.

. Lei $\mathrm{n}^{\circ} 11.124$ de 16 de junho de 2005. Dispõe sobre o Sistema Nacional de habitação de Interesse Social - SNHIS, Cria o Fundo Nacional de Interesse Social FNHIS e Institui o Conselho Gestor do FNHIS. Brasil.

. Lei $\mathrm{n}^{\circ} 10.257$ de 10 de julho de 2001. Estabelece diretrizes gerais da política urbana. Estatuto das Cidades. Brasil.

. Lei Complementar $n^{\circ} 155$ de 28 de dezembro de 2007. Dispõe sobre a Política Urbana do Município de Palmas. Palmas.

LEITE, C.; AWAD, J. di C. M. Cidades Sustentáveis, Cidades Inteligentes: desenvolvimento sustentável num planeta urbano. Porto Alegre: Bookman, 2012.

Ministério das Cidades. 2005. Cadernos técnicos de orientação para implementação dos instrumentos do Estatuto da Cidade. Outorga Onerosa do Direito de Construir. Brasília.

Ministério das Cidades. Guia para regulamentação e implementação de Zonas Especiais de Interesse Social - Zeis em vazios urbanos. Brasília: 2009.

NEWTON, P. Urban Form and Environmental Performance. In.: Williams, K.; Burton, E.; Jenks, M., (Ed.) Achieving Sustainable Urban Form (p. 46-53). Londres, E\&FN Spon, 2000.

OLIVEIRA, F. A outorga onerosa do direito de construir como instrumento de promoção do reequilíbrio urbano. 2015. Fortaleza. Disponível em: http://www.publicadireito.com. br/conpedi/manaus/arquivos/anais/salvador/fernanda_maria_diogenes_de_menezes_ oliveira.pdf Acesso em: 25 nov. 2018.

Organizações das Nações Unidas - ONS. 2012. Como Construir Cidades Mais Resilientes. Um Guia para Gestores Públicos Locais. Uma contribuição à Campanha Global 2010-2015 Construindo Cidades Resilientes - Minha Cidade está se preparando! Genebra.

PAULA, R. Permanência e Fissuras. ZEIS vazias na experiência recente da política habitacional de Belo Horizonte. 2018. 197p. Dissertação (Mestrado) em Arquitetura e Urbanismo. Universidade de Brasília. Brasília.

PAZ, T. A aplicação da outorga onerosa do direito de construir: o caso da cidade de Palmas-TO. XVII ENANPUR. São Paulo: 2017.

RAMOS, Leonardo Serrat de Oliveira. MORADIA DIGNA: Plurissignificação Necessária para a Compreensão do Mínimo Existencial. 2011. 82p. TCC (Bacharel) em Ciências Jurídicas e Sociais. Universidade Federal do Rio Grande do Sul- UFRGS. Porto Alegre.

RIBAS, Otto. A sustentabilidade das cidades: os instrumentos de gestão urbana e a construção da qualidade ambiental. 2003. 253p. Tese (doutorado) em Desenvolvimento Sustentável. Área de concentração Política e Gestão Ambiental. CDS / UnB. Brasília. 
ROGERS, R e Gumuchdjian, P. Cidades para um pequeno planeta. Editorial Gustavo Gili, Barcelona: 2001.

ROLNIK, Raquel. Guia do Estatuto da Cidade. Câmara dos Deputados, Brasília: 2001.

RUEDA, S. Modelos e indicadores para ciudades más sostenibles: taller sobre indicadores de huella e calidad ambiental. Barcelona, Fundación Forum Ambiental / Departament de Medi Ambient de la Generalitat de Catalunya. Barcelona: 2000

RUEDA, S. Modelos de Ordenacion Del Território Más Sostenibles, 2002. [Internet] Disponível em:< http://habitat.aq.upm.es/boletin/n32/asrue.html\#3> [Acesso em jul. 2012].

SACHS, I. Caminhos para o Desenvolvimento Sustentável. Rio de Janeiro: Garamond. Rio de Janeiro: 2002

SALES, P. 2005. São Paulo: crítica, plano e projeto. Parte 2. Operação Urbana Faria Lima: relatório de avaliação crítica. Arquitextos, Texto Especial no 300. Portal Vitruvius. São Paulo. www.vitruvius.com.br/arquitextos/arq000/esp300.asp acesso em 25 nov. 2018.

SANTOS, C.; Hardt, L. 2013. Qualidade Ambiental e de Vida nas Cidades. In: GONZALES, S.; FRANCISCONI, J. G.; PAVIANI, A. (Orgs.). Planejamento e Urbanismo na Atualidade Brasileira. Objeto, teoria, prática. Rio de Janeiro: Livre Expressão. p. 151-168.

SEGETH, Secretaria de Gestão do Território e Habitação. 2017. Zonas Especiais de Interesse Social para provimento habitacional: Estudo de proposição. Caderno de ZEIS. Brasília. Disponível em: http://www.segeth.df.gov.br/wp-conteudo/uploads/2017/10/1_ Caderno-ZEIS-Versão-Final.pdf Acesso em: 03/11/2018.

SILVA, Sandra R. Mota. Indicadores de Sustentabilidade Urbana: as perspectivas e as limitações da operacionalização de um referencial sustentável. 2000. 260p. Dissertação (Mestrado) em Engenharia Urbana. UFSCar. São Paulo.

SOUSA, André Lima. O Território da Habitação no Processo do Plano Diretor Participativo da Cidade de Fortaleza/CE, Brasil. Scripta Nova. Revista Electrónica de Geografía y Ciencias Sociales. [En línea]. Barcelona: Universidad de Barcelona, 1 de agosto de 2010, vol. XIV, no 331 (9). <http://www.ub.es/geocrit/ sn/sn-331/sn-331-9. htm>.

TUDELA, F. Para uma cultura de sustentabilidade urbana. In: NEIRA ALVA, Eduardo. Metrópoles (in)sustentáveis. Rio: Relume Dumará. Rio de Janeiro: 1997. 
